\title{
Incidence of Epilepsy in Adults with Cerebral Palsy and Secondary Health Outcomes: A Review and Proposed Feasibility Study
}

\author{
Tatiana Oliveira $^{1^{*}}$, James Carollo ${ }^{2,3}$, David Robertson ${ }^{3}$, Zhaoxing Pan ${ }^{2,4}$ and Patricia Heyn ${ }^{2,3}$ \\ ${ }^{1}$ Department of Pediatrics, JFK Partners, University of Colorado Anschutz Medical Campus, USA \\ ${ }^{2}$ Department of Physical Medicine and Rehabilitation, University of Colorado Anschutz Medical Campus, USA \\ ${ }^{3}$ Center for Gait and Movement Analysis, Children's Hospital Colorado, USA \\ ${ }^{4}$ Department of Biostatistics and Informatics, Colorado School of Public Health, USA
}

"Corresponding author: Tatiana Oliveira, Center for Gait and Movement Analysis, Children's Hospital Colorado, USA, Tel: 1 (720) 777 1234; E-mail: tatiana.oliveira@ucdenver.edu

Rec Date: Jul 29, 2014; Acc Date: Oct 15, 2014; Pub Date: Oct 18, 2014

Copyright: (C) 2013 Oliveira T, et al. This is an open-access article distributed under the terms of the Creative Commons Attribution License, which permits unrestricted use, distribution, and reproduction in any medium, provided the original author and source are credited.

\begin{abstract}
Cerebral palsy is one of the most common chronic childhood disorders, occurring in 2-2.5 of every 1000 live births; it is a persistent disorder of movement and posture caused by non-progressive lesions of the immature brain. Epilepsy is an important problem in children with cerebral palsy, with past studies showing an average incidence of epilepsy in about one-third in cases of cerebral palsy. Epilepsy is a disorder of the brain characterized by an enduring predisposition to generate seizures, common in patients who have other factors (such as cerebral palsy) that are associated with a very high likelihood of a persistently lowered seizure threshold and therefore a high recurrence risk.
\end{abstract}

A few studies were conducted in the past analyzing the correlation of cerebral palsy and epilepsy in children; however, no study has been conducted yet evaluating the evolution of cerebral palsy in the transition from childhood to adulthood, and how the incidence, prevalence and clinical course of epilepsy change in such a time lapse. Furthermore, no studies yet evaluated the classification of seizures in this adult population, their correlations to cerebral palsy and its degrees of severity, and associated secondary health conditions, causing epidemiological data to be lacking in that regard.

This aim of this manuscript is to introduce to the reader the current evidence regarding epilepsy in adults with cerebral palsy, as well as present recommendations for future research.

Keywords: Cerebral Palsy; Epilepsy

\section{Introduction}

People with disabilities have long been marginalized by society's unwillingness to include them [1]. These individuals have often been alienated and excluded from their local communities, educational systems and workplaces; in some important ways they have been denied access to the very fabric of society [1]. Despite the great strides made and best intentions of legislation such as the Americans with Disabilities Act (ADA) and the Individuals with Disabilities Education Act (IDEA), there are still social and attitude barriers which limit inclusion and environmental barriers that limit access to the community and health care resources. The 2010 census showed that $18.7 \%$ of the U.S. population aged six and older had some type of physical, sensory, or cognitive disability, and approximately 28.6 million American households had a person with a disability. The likelihood of having a disability varied by age - from 4 percent of people under 18 years old, to 10 percent of people 18 to 64 years old, and to 37 percent of those 65 and over [2]. In terms of reduced productivity, economic hardship, loss of independence, and the sheer human cost associated with their often unsatisfactory quality of life, these statistics provide strong evidence of need and support the notion that aggressive action is required if individuals with disabilities are to have the same opportunities as other Americans.

Cerebral palsy is one of the most common childhood disorders, chronic in nature, and occurs in 2-2.5 of every 1000 live births [3-5]. More than 100,000 Americans under the age of 18 years are estimated to have some degree of neurological disability due to cerebral palsy [6]. Cerebral palsy is generally defined as a persistent disorder of movement and posture caused by nonprogressive defects or lesions of the immature brain [7]. It is caused by damage or injury to one or more specific areas of the brain, and usually occurs during fetal development, before, during, or shortly after birth, or during infancy [7]. Since the original injury can affect any portion of the growing brain at any stage of development, the combination and severity of symptoms are highly variable, and rarely two children with cerebral palsy display the same clinical picture (Table 1).

Both the prevalence of cerebral palsy at birth and life expectancy of children with cerebral palsy are increasing worldwide, a trend attributable to improved obstetric and neonatal care, and the subsequent increased survival of infants with low or very low birth weight [8] who may suffer brain damage or have developmental defects that result in the diagnosis of cerebral palsy $[9,10]$. Because of improved diagnosis and treatment as children, most individuals with cerebral palsy are now surviving well into adulthood and their life span 
is approaching that of the general population [11]. In fact, several authors have established that adults with cerebral palsy may experience significant age-related health changes earlier in life than their non-disabled peers [12]. An increasing cerebral palsy population together with the increased frequency of their health complains, combined with the apparent lack of understanding of their ongoing treatment by many adult health care providers lead to the urgent development of public health initiatives. Consequently, the cerebral palsy International Research Foundation, the American Academy for
Cerebral Palsy \& Developmental Medicine, and Reaching for the Stars, a family support group, sponsored an expert workshop in Sept. 2008 to review current knowledge and develop a blueprint for future research [12]. The consensus from this workshop was that a pressing need exists for longitudinal studies of adults with cerebral palsy, using comprehensive outcome variables of physical function, health status, and qualities of life, to better understand how cerebral palsy changes over a person's lifetime.

\begin{tabular}{|c|c|c|c|}
\hline Type & Subtype & $\begin{array}{l}\text { Physical examination findings/associated } \\
\text { impairments }\end{array}$ & prognosis \\
\hline \multirow[t]{4}{*}{ spastic } & $\begin{array}{l}\text { Diplegia:L } 30 \%-40 \% \text { of spastic } \mathrm{CP} ; \\
\% 0 \% \text { were born preterm }\end{array}$ & $\begin{array}{l}\text { Spasticity in lower extremeties (can effect } \\
\text { upper but to a lesser degree); risks for } \\
\text { strabismus;learning, attention, and } \\
\text { communication disorders common }\end{array}$ & $\begin{array}{l}30 \% \text { will have cognitive impairmants; } 80 \%-90 \% \text { will } \\
\text { ambulate with or without assistance; independent in } \\
\text { self-care, sphincter control }\end{array}$ \\
\hline & $\begin{array}{l}\text { Hemiplegia: } 20 \%-30 \% \text { of specific } \mathrm{CP} ; \\
\text { associated with strokes, vascular } \\
\text { malformations, unilateral IVH or PVL }\end{array}$ & $\begin{array}{l}\text { Unilateral spasticity; early asymmetry in } \\
\text { movements and/or functional abilities (i.e, } \\
\text { asymmetrical crawl or early hand } \\
\text { preferences); risk for visual field cut, mild to } \\
\text { moderate cognitive and communication } \\
\text { disorders, high rate of partial seizures }\end{array}$ & $\begin{array}{l}>60 \% \text { will have normal intelligence and with } \\
\text { ambulate with or without assistance by } 36 \text { mo of } \\
\text { age; difficulty dressing with fasteners, independent } \\
\text { in self-care and sphincter control }\end{array}$ \\
\hline & $\begin{array}{l}\text { Quadriplegia: } 10 \%-15 \% \text { of spastic } \\
\mathrm{CP} \text {; associated with severe asphyxia } \\
\text { in all in all infants; severe IVH and } \\
\text { PVL in preterm infants }\end{array}$ & $\begin{array}{l}\text { All extremeties affected, as well as trunk and } \\
\text { oral muscularure }\end{array}$ & $\begin{array}{l}\text { Up to } 50 \% \text { eventually achieve some degree of } \\
\text { assisted ambulation, } 25 \% \text { will be severely impaired } \\
\text { and nonambulatory; approximate } 50 \% \text { risk of } \\
\text { epilepsy, mental retardation, deathness and severe } \\
\text { visual impairment; self-care possible in many; } \\
\text { communication and continency limitations common }\end{array}$ \\
\hline & Monoplegia/triplegia & Monoplegia: one limb triplegia:three limbs & $\begin{array}{l}\text { Rare; disability dependent on affected limb and } \\
\text { severity }\end{array}$ \\
\hline \multirow[t]{2}{*}{ Nonspastic } & $\begin{array}{l}\text { Dyskinetic: Damage to basal ganglia } \\
\text { or thalamus (deep motor neurons) }\end{array}$ & $\begin{array}{l}\text { Athetoid: Hypotonic infant with chorea } \\
\text { (random, rapid, jerky movement patterns) and } \\
\text { athetosis (slow, writhing movement patterns) } \\
\text { develop between } 1-3 \text { mo Dystonic: Infants } \\
\text { present with rigid posturing of neck and trunk }\end{array}$ & $\begin{array}{l}\text { Speech problems such as dysarthria are common; } \\
30 \%-78 \% \text { will have normal intelligence; upto } 50 \% \\
\text { will achieve some degree of ambulation }\end{array}$ \\
\hline & $\begin{array}{l}\text { Ataxic: Damage to neurons in } \\
\text { cerebellum }\end{array}$ & $\begin{array}{l}\text { Problem with voluntary movement, balance, } \\
\text { depth perception }\end{array}$ & $\begin{array}{l}\text { Commonly oral motor difficulties (swallowing } \\
\text { drooling, abnormal speech patterns); tremors and } \\
\text { poor head control common as well problems with } \\
\text { overall coordination; wide-based, unsteady gait in } \\
\text { ambulatory children }\end{array}$ \\
\hline
\end{tabular}

Table 1: Types and subtypes of CP in infancy/childhood

It is generally thought that cerebral palsy is a disorder that stabilizes itself by the adult years; however, cerebral palsy is a life-long disorder with special challenges in every decade of life [13]. An important milestone for any young person with a disability is the transition from the children's health system to adult-centered care. Healthcare for individuals with cerebral palsy must pay attention to transition to adulthood services to ensure that as adults they receive age appropriate care such as routine comprehensive health assessments and health promotion [14-16].

Several other neurologic disabilities often accompany cerebral palsy [7]. Approximately one third to half of all children with this disease have epilepsy [17-21], and the rate of combined epilepsy and cerebral palsy is of 0.8 per 1,000 live births [22]. The high frequency of epileptic seizures and cognitive or perceptual disorders among patients who have cerebral palsy suggests that these disorders have common or related origins. Epilepsy is a disorder of the brain characterized by an enduring predisposition to generate epileptic seizures, and by the neurobiological, cognitive, psychological, and social consequences of this condition. The definition of epilepsy has been outlined as at least two unprovoked seizures more than 24 hours apart, and the revised operational definition by the International League Against Epilepsy ILAE 2010 [23] also says that epilepsy can be considered to be present after one unprovoked seizure in individuals who have other factors that are associated with a very high likelihood of a persistently lowered seizure threshold and therefore a high recurrence risk (such as cerebral palsy).

A few studies over the last three decades were conducted studying the epidemiological features of cerebral palsy and epilepsy in the pediatric population [17-21,24]. However, as cerebral palsy is generally seen as a childhood disorder, no studies have been done on the cerebral palsy population who reach adulthood. An analysis in depth is lacking of the segment of the previously non-affected cerebral palsy 
individuals who might have presented epilepsy for the first time in adulthood, and how the disorder evolves and behaves in this older population. As it is with other childhood chronic ailments, the transition to adulthood may bring significant changes in clinical features and associated impairments, cardiovascular and metabolic changes, shifts in severity and disease course that require adaptations in preventative and palliative treatments targeted to this population.

Several types of epilepsies manifest in specific ages, some of them being prevalent in the childhood/young adulthood (Table 3). These epilepsies are unaccounted for in the current statistics for the incidence of epilepsy in individuals with cerebral palsy, since the studies available evaluated subjects in the pediatric age range. In addition, the types and classification of seizures (Table 2) in this specific population of adults with cerebral palsy and epilepsy has not been studied in depth yet, neither has its epidemiology.

\section{Discussion}

Epilepsy, one of the many secondary disabilities that are associated with cerebral palsy, can pose severe limitations to the patient who already has a physical challenge in integrating in society and the work force. There is an urgent gap to fill the current understanding of the association between cerebral palsy and epilepsy, and its secondary health consequences, focusing in the epidemiological factors and evolution of the disease through the years, from onset (Table 1) to transition to adulthood [16], current status, and its correlations with the myriad of disabilities the patients with cerebral palsy present, such as cognitive and physical limitations, and the subsequent sedentary lifestyle (Figure 1).

Children with cerebral palsy receive a considerable level of medical care during their school age years; however once they reach adulthood and are no longer part of the school system their level of care drops dramatically and they do not have access to the same benefits that were available during childhood [25]. The epidemiology of cerebral palsy and its association with epilepsy has been studied sparsely during the past three decades; of special importance is the work of Carlsson, Hagberg and Olsson, analyzing clinical and etiological aspects of cerebral palsy in a retrospective, population-based study, with children from 6 to 14 years of age [17] in Sweden. Of note is also the work of Singhi et al., studying epilepsy in children with cerebral palsy, in a prospective analysis with children with cerebral palsy and epilepsy from 1 to 14 years of age in India [18]. Other studies, always focused on the pediatric population with cerebral palsy and epilepsy, have also been conducted over the years [19-21,24].

In these studies, the incidence rate of epilepsy among children with cerebral palsy has varied approximately from 15 to 49 percent. The likelihood of epilepsy, extrapyramidal abnormalities, and severe cognitive impairment is higher among those with quadriplegia than among those with diplegia or hemiplegia [18]. However, no specific study, over a large span of years and engulfing the delicate transition from childhood to adulthood has ever been performed involving cerebral palsy and epilepsy. We believe this percentage must be much higher than the current pediatric statistics show, considering the fact that some of these patients will develop age-related epilepsies after becoming adults (Table 3). Further studies are vital to clearly define this actual incidence rate, and aid in comprehensive and focused protocols for treatment and morbidity/mortality prevention for this adult population, often treated without their specific characteristics in mind.
In addition, this specific population of older subjects with cerebral palsy and epilepsy has not been studied regarding types and classifications of seizures (Table 2), its severity, and its epidemiology. We currently do not know which seizure modalities are more prevalent in adults with cerebral palsy, rate of epilepsy treatment refractoriness, or specific age of onset. Several types of epilepsies manifest in specific ages, some of them being prevalent in the childhood/young adulthood transition (Table 3). These epilepsies are unaccounted for in the current statistics for the incidence of epilepsy in individuals with cerebral palsy, since the studies available evaluated subjects in the pediatric age range.

\begin{tabular}{|l|}
\hline Generalized seizures \\
\hline Tonic-clonic (in any combination) \\
\hline Absence \\
\hline Typical \\
\hline Atypical \\
\hline Absence with special features \\
\hline Myoclonic absence \\
\hline Eyelid myoclonia \\
\hline Myoclonic \\
\hline Myoclonic \\
\hline Myoclonic atonic \\
\hline diagnosis. This is not considered a classification category. however. \\
\hline Myoclonic tonic \\
\hline Clonic \\
\hline Tonic \\
\hline Atonic \\
\hline Focal seizures \\
\hline Unknown \\
\hline Epileptic spasms \\
\hline Seire that cannot be clearly diagnosed into one of the preceding categories \\
\hline
\end{tabular}

Table 2: Classification of seizures. Extracted from the Revised terminology and concepts for organization of seizures and epilepsies: report of the ILAE Commission on Classification and Terminology, 2005-2009. Epilepsia, 2010 [19].

Different treatments are required for different types of seizures; therefore, a better epidemiological understanding of epilepsy in adults with CP will aid on the development of optimal treatment protocols, including epilepsy surgery for a population not very frequently considered for that approach [26].

The developmental delays that often accompany cerebral palsy keep some body structures and functions from developing to their full capacity and level of performance. As a consequence, organ systems such as the cardiovascular system and pulmonary system have to work harder to compensate for the functional debts imposed by cerebral palsy, leading to premature aging of these systems [12]. Furthermore, 
the incidence and prevalence of cardiovascular disease and metabolic alterations has not been analyzed yet in this population after transitioning to adulthood. Additionally, some antiepileptic medications for seizure control are known for causing weight gain [27]; many patients with epilepsy also benefit from the adoption of a ketogenic diet for better control of severity and frequency of seizures [28-32] which includes patients with associated cerebral palsy. We hypothesize that, due to the physical limitations of this particular group and consequently, their sedentary lifestyle, the cardiovascular/ metabolic profile may portray several specific patterns correlating with the severity of their impairment, added to the effects caused by medications and an epilepsy-specific diet [33,34] (Figure 1). In a population already afflicted by the difficult conditions that cerebral palsy and epilepsy bring, a better understanding of the associated secondary ailments deriving from it, such as cardiovascular and metabolic diseases, is of vital importance for the clinician to more optimally treat such patients (such as choosing better suited antiepileptic medications) and for preventative measures to be established (diet and exercise counseling, and strict/consistent monitoring).

\begin{tabular}{|c|c|c|}
\hline $\begin{array}{l}\text { Aim 1: To determine correlation between CP \& } \\
\text { Epilepsy and its combined epidemiology thorough } \\
\text { childhood to adulthood }\end{array}$ & $\begin{array}{l}\text { Aim 2: To evaluate mental status; intellectual and } \\
\text { psychological secondary outcomes; self-perceived } \\
\text { level of disability and quality of life. }\end{array}$ & $\begin{array}{l}\text { Aim 3: To analyze the epidemiology of secondary } \\
\text { health issues such as cardiovascular and metaboli } \\
\text { risk increase. }\end{array}$ \\
\hline 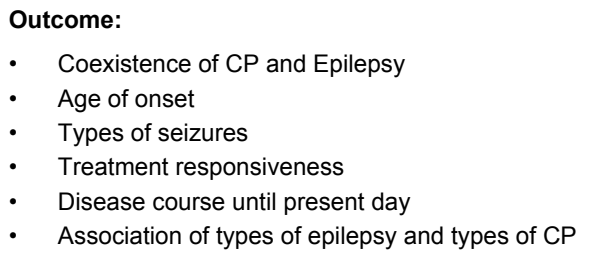 & $\begin{array}{l}\text { Outcome: } \\
\text { - Cognitive status and abilities }\end{array}$ & $\begin{array}{l}\text { Outcome: } \\
\text { - } \quad \text { Metabolic profile, BMI, blood pressure }\end{array}$ \\
\hline $\begin{array}{l}\text { Measurements: } \\
\text { - Previous medical records, current medical } \\
\text { history, interviews and physical examination }\end{array}$ & $\begin{array}{l}\text { Measurements: } \\
\text { - } \quad \text { Standardized cognitive and mood assessments, } \\
\text { such as: } \\
\text { - Wechsler's WAIS IV/WMS IV subscales [38,39]. } \\
\text { - } \quad \text { NIH Toolbox for Cognitive Measures [40]. } \\
\text { - } \quad \text { General Self-Efficacy Scale (GSES-12) [41]. } \\
\text { - Center for Epidemiological studies Depression } \\
\text { Scale (CES-D) [42]. } \\
\text { - NIH Patient Reported Outcomes Measurement } \\
\text { System (PROMIS) and Health-Related Quality of } \\
\text { Life [43]. } \\
\text { The World Health Organisation Disaility } \\
\text { assessment Schedule (WHODAS II) [44]. } \\
\text { Mayo Clinic Short Mental Status Examination } \\
\text { (MMSE) [45]. }\end{array}$ & $\begin{array}{l}\text { Measurements: } \\
\text { - Blood sample analysis (glucose, insulin, lipid } \\
\text { pane), physical examination } \\
\text { - } \quad \text { Diet evaluation } \\
\text { - } \quad \text { Antiepileptic medications used }\end{array}$ \\
\hline $\begin{array}{l}\text { Public Knowledge: } \\
\text { - This data will help us define the epidemiological } \\
\text { profile of epilepsy in individuals with } C P \text {, now in a } \\
\text { complete fashion by including the adult-onset } \\
\text { epilepsies to the current pediatric-based } \\
\text { evidence }[18,20,32-34,36]\end{array}$ & $\begin{array}{l}\text { Public Knowledge: } \\
\text { - This data will help us define a concern for } \\
\text { psychological and cognitive abnormalities } \\
\text { (depression, cognitive decline) in the population } \\
\text { with CP and epilepsy, and its severity. }\end{array}$ & $\begin{array}{l}\text { Public Knowledge: } \\
\text { - This data will help us identify level of risk for } \\
\text { chronic cardiovascular and metabolic disease in } \\
\text { adult patients with } \mathrm{CP} \text { and epilepsy, and its } \\
\text { severity }\end{array}$ \\
\hline $\begin{array}{l}\text { Clinical Practice: } \\
\text { - This data will help health professionals in the } \\
\text { guidance, recommendation and support of health } \\
\text { services related to the epilepsy diagnosis and } \\
\text { care designed specifically for individuals with CP } \\
\text { transitioning from pediatric care to the adult[- } \\
\text { based health system, since many general } \\
\text { practioners are not familiar with the peculiarities } \\
\text { of this population [12,14-16]. }\end{array}$ & $\begin{array}{l}\text { Clinical Practice: } \\
\text { - This data will help in the creation of new } \\
\text { protocols for mental health services, with the } \\
\text { intent to prevent and treat cognitive ailments in } \\
\text { this specific population. }\end{array}$ & $\begin{array}{l}\text { Clinical Practice: } \\
\text { - This data will help health professionals in the } \\
\text { guidance, recommendation and support of } \\
\text { preventive health services related to diet and } \\
\text { exercise orientation, tailored to epilepsy and CP } \\
\text { status in those patients. Prevention and } \\
\text { treatment of cardiovascular and metabolic } \\
\text { disease in this specific population will help } \\
\text { significantly reduce mortality/morbidity in an } \\
\text { already health-compromised population. }\end{array}$ \\
\hline
\end{tabular}

Table 3: Specific Aims that need to be addressed by future research and their result benefits for public knowledge and clinical practice.

Finally, mental health issues can also be of concern as someone with cerebral palsy grows older and their level of disability increases, making the inclusion in the society more difficult. The rate of depression is three to four times higher in people with disabilities such as cerebral palsy $[6,35,36]$. This is another secondary outcome that needs to be better understood and addressed in order to improve health status and quality of life of this specific population (Figure 2). 
Page 5 of 6

\section{Conclusion and Future Studies}

As the prevalence of cerebral palsy in the adult population increases due to improved medical care [37], new data is necessary to target this growing population, aiding clinicians and multidisciplinary teams to develop protocols and better provide long-term care to the specific needs of the adults with cerebral palsy and its associated disorders, such as epilepsy [16]. Furthermore, patients with cerebral palsy and epilepsy present a specific challenge regarding cardiovascular and metabolic profiles, due to the degree of severity of their impairment, diet such as ketogenic diet for improved control of seizure activity [29-33], antiepileptic medications [27], and secondary sedentary lifestyle. The transition from childhood to adulthood is the mark of entry in the workforce; the likelihood of having a disability is of 10 percent of people 18 to 64 years old in the US [2]. In 2008, the federal government spent an estimated $\$ 357$ billion dollars on programs for working-age people with disabilities, representing 12 percent of total federal outlays [2]. Therefore, improving the health outcomes of these individuals can help more of them to be included in the workforce, consequently also reducing social and tax-payer costs.

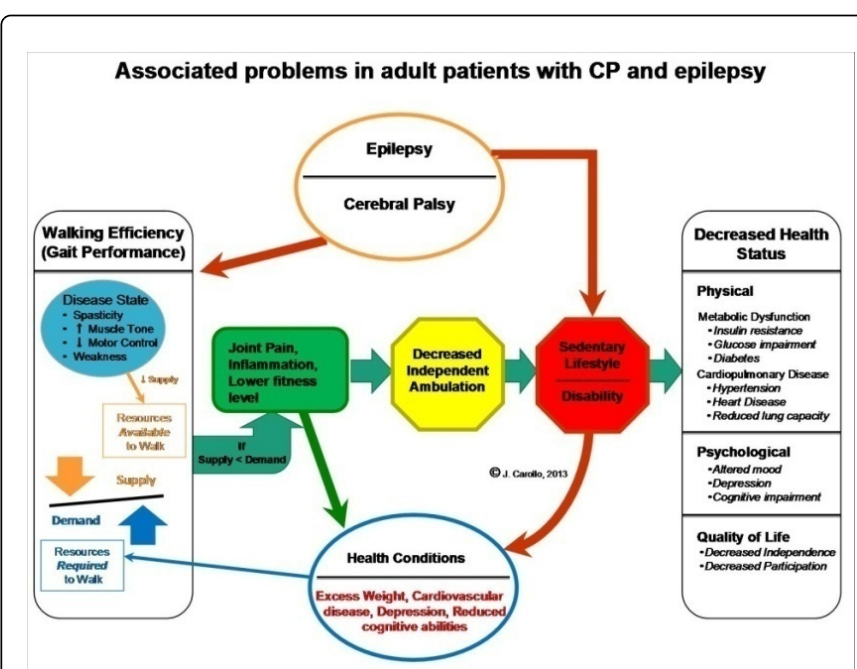

Figure 1: Associated problems in adults with cerebral palsy and epilepsy. Created by James Carollo, PhD, modified (with permission) by Tatiana Oliveira, MD.

Cerebral palsy is one of the most common chronic childhood disorders, affecting millions of Americans and individuals around the world; beyond the physical impairment it can inflict in patients, other associated clinical ailments can worsen disability and pose even more difficulties for inclusion in society, such as epilepsy, which affects about one-third to half of cases of cerebral palsy. Epilepsy is a disorder of the brain characterized by an enduring predisposition to generate epileptic seizures, and by the neurobiological, cognitive, psychological, and social consequences of this condition. Further studies are needed to better understand: 1) the epidemiology of cerebral palsy and epilepsy after adulthood; 2) its development and evolution throughout the years; and 3) epilepsy and cerebral palsy and its associated health conditions. Therefore, we are proposing a pilot feasibility study that has the potential to provide preliminary data to aid clinicians and multidisciplinary clinical teams to treat more effectively adults with cerebral palsy, as well as develop effective public health initiatives (Figure 2).
Our goal is to study longitudinally a sample of 400 adults with cerebral palsy (age range of 18 to 40 years old), currently in the database registry of the Center for Gait and Movement Analysis (CGMA) and Children's Hospital Colorado, who previously were evaluated and treated as children. A retrospective analysis of their medical records will be performed, collecting statistical data such as the epidemiology of epilepsy in those individuals with cerebral palsy, age of onset, type and severity of cerebral palsy, type of seizures (classified according to the 2010 International League Against Epilepsy - ILAE guidelines) [23], level of responsiveness to treatment, and disease course until the present time. A cross-sectional evaluation will also be performed by obtaining current medical history; we will be studying current status of disease, adult-onset epilepsies and correlations with other problems associated with cerebral palsy, such as decrease in physical abilities and subsequent sedentary lifestyle, diet and antiepileptic medications used, cognitive and mood status (by use of standardized assessments [38-45]) and cardiovascular/metabolic alterations (by use of blood tests and physical examination). According the results obtained, we hope this pilot study will aid in the confection of future studies on this aging and often forgotten population.

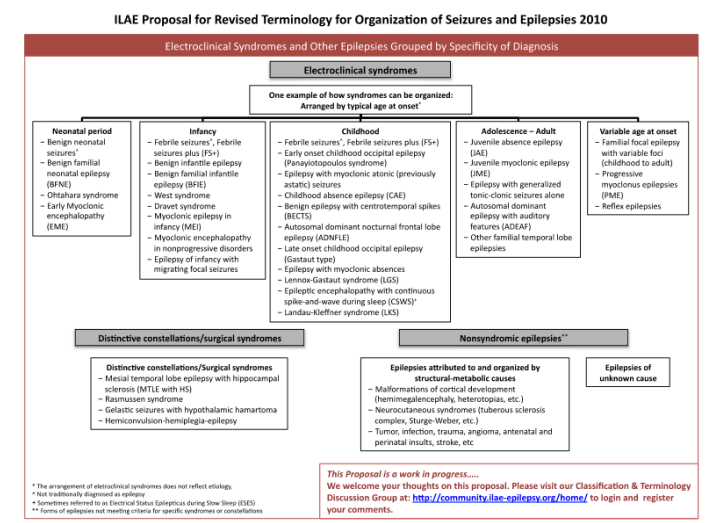

Figure 2: ILAE Organization of Seizures and Epilepsies 2010.

\section{References}

1. Ward MJ (2009) A Personal Perspective on Historical Views of Disability. In Disability and Public Health. CE Drum, GL Krahn, H Bersani (Eds.) Chapter 4, pp. 45-64. American Public Health Association; American Association on Intellectual and Developmental Disabilities, Washington, DC.

2. Brault, Matthew W (2012) “Americans With Disabilities: 2010". Current Population Reports, U.S. Census Bureau, Washington, DC.

3. Odding E, Roebroeck ME, Stam HJ (2006) The epidemiology of cerebral palsy: incidence, impairments, and risk factors. Disabil Rehabil 28: 183-191.

4. Blair E (2010) Epidemiology of the Cerebral Palsies. Orthop Clin North Am 41: 441-455.

5. Krägeloh-Mann I, Cans C (2009) Cerebral Palsy Update. Brain Dev 31: 537-544.

6. Phipps S, Roberts P (2012) Predicting the Effects of Cerebral Palsy Severity on Self-Care, Mobility, and Social Function. Am J Occup Ther 66: 422-429.

7. Russman BS, Ashwal S (2004) Evaluation of the child with cerebral palsy. Seminar in Pediatric Neurology, 11: 47-57. 
Citation: Oliveira T, Carollo J, Robertson D, Pan Z, Heyn P (2014) Incidence of Epilepsy in Adults with Cerebral Palsy and Secondary Health Outcomes: A Review and Proposed Feasibility Study. J Neurol Disord 2: 188. doi:10.4172/2329-6895.1000188

Page 6 of 6

8. Pharoah PO, Platt MJ, Cooke, T (1996) The changing epidemiology of cerebral palsy. Arch Dis Child Fetal Neonatal Ed 75: F169-173.

9. Vincer MJ, Allen AC, Joseph KS, Stinson D, Scott H, et al. (2006) Increasing prevalence of cerebral palsy among very preterm infants: a population-based study. Pediatrics 118: e1621-e1626.

10. http://www.medlink.com/medlinkcontent.asp

11. Haak BS, Lenski M, Hidecker MJ, Li M, Paneth N (2009) Cerebral palsy and aging. Dev Med Child Neurol : 16-23.

12. Tosi LL, Maher N, Moore DW, Goldstein M, Aisen ML (2009) Adults with cerebral palsy: a workshop to define the challenges of treating and preventing secondary musculoskeletal and neuromuscular complications in this rapidly growing population. Dev Med Child Neurol : 2-11.

13. Lankasky K (2004) A consumer's perspective on living with a disability: how change in function affects daily life. Aging with a Disability: What the Clinician Needs to Know, The Johns Hopkins University Press, Baltimore, MD, USA.

14. Srivastava R, Stone B (2011) Survival of children and young people with cerebral palsy. Dev Med Child Neurol 53 : 808-814.

15. Rimmer JH (1999) Health promotion for people with disabilities: the emerging paradigm shift from disability prevention to prevention of secondary conditions. Phys Ther 79: 495-502.

16. Appleton RE, Chadwick D, Sweeney A (1997) Managing the teenager with epilepsy: paediatric to adult care. Seizure 6: 27-30.

17. Wyllie E, Gupta A, Lachhwani DK (2006) The Treatment of Epilepsy: Principles \& Practice 4th Edition. Lippincott Williams \& Wilkins.

18. Carlsson M, Hagberg G, Olsson I (2003) Clinical and aetiological aspects of epilepsy in children with cerebral palsy. Dev Med Child Neurol. 45:371-376

19. Berg AT, Berkovic SF, Brodie MJ, Buchhalter J, Cross JH, et al. (2010) Revised terminology and concepts for organization of seizures and epilepsies: report of the ILAE Commission on Classification and Terminology, 2005-2009. Epilepsia, 51: 676-685.

20. Singhi PD, Jagirdar S, Khandelwal N, Malhi P (2003) Epilepsy in children with cerebral palsy. Journal of Child Neurology 18: 174-179.

21. Stafstrom CE, Rho JM (2004) Epilepsy and the Ketogenic Diet. Humana Press,Totowa, N.J.

22. Kossoff E (2011) Ketogenic diets: treatments for epilepsy and other disorders. Demos Health, New York, NY.

23. Freeman JM, Freeman JB, Kelly MT (2000) The Ketogenic Diet: Treatment for Epilepsy. Demos Health, New York, NY.

24. Kossoff EH et al (2013) Transitioning pediatric patients receiving ketogenic diets for epilepsy into adulthood. Seizure 22: 487-489.

25. Cross JH (2013) New Research With Diets and Epilepsy. Journal of Child Neurology 28: 970-974.

26. Vining, E. P. G. (2008), Long-term health consequences of epilepsy diet treatments. Epilepsia, 49: 27-29.

27. Foster GD, Wyatt HR, Hill JO, McGuckin BG, Brill C, et al. (2003) A multi-center, randomized, controlled clinical trial of the Atkins diet. NE J Med 348: 282-290.

28. Pickrell WO, Lacey AS, Thomas RH, Smith PE, Rees MI (2013) Weight change associated with antiepileptic drugs. J Neurol Neurosurg Psychiatry 84: 796-799.
29. Hirsh AT, Gallegos JC, Gertz KJ, Engel JM, Jensen MP (2010) Symptom Burden in Individuals with Cerebral Palsy. Journal of Rehabilitation Research \& Development 47: 863-875.

30. http://www.ninds.nih.gov/disorders/cerebral_palsy/ detail_cerebral_palsy.htm

31. Ng SY, Dinesh, SK Tay SKH, Lee EH (2003) Decreased access to health care and social isolation among young adults with cerebral palsy after leaving school. Journal of Orthopaedic Surgery 11: 80-89.

32. Sellier E, Uldall P, Calado E, Sigurdardottir S, Torrioli MG, et al (2012) Epilepsy and cerebral palsy: Characteristics and trends in children born in 1976-1998. Eur J Paediatr Neurol 16:4 8-55.

33. El-Tallawy HN, Farghaly WM, Shehata GA, Badry R, Rageh TA (2014) Epileptic and cognitive changes in children with cerebral palsy: an Egyptian study. Neuropsychiatr Dis Treat 10: 971-975.

34. Odding E, Roebroeck ME, Stam HJ (2006) The epidemiology of cerebral palsy: incidence, impairments and risk factors. Disabil Rehabil 28:183-191.

35. Binks JA, Barden WS, Burke TA, Young NL (2007) What do we really know about the transition to adult-centered health care? A focus on cerebral palsy and spina bifida. Arch Phys Med Rehab 88: 1064-1073.

36. Gururaj AK, Sztriha L, Bener A, Dawodu A, Eapen V (2003) Epilepsy in children with cerebral palsy. Seizure 12: 110-114.

37. Olsson I, Danielsson S, Hedström A, Nordborg C, Viggedal G, et al. (2013) Epilepsy surgery in children with accompanying impairments. Eur J Paediatr Neurol 17: 645-650.

38. Wechsler, D. (2008a). Wechsler Adult Intelligence Scale-Fourth Edition. San Antonio, TX: Pearson.

39. Wechsler, D. (2009). Wechsler Memory Scale-Fourth Edition (WMSIV) technical and interpretive manual. San Antonio, TX: Pearson.

40. Akshoomoff N, Beaumont JL, Bauer PJ, Dikmen SS, Gershon RC et al. (2013) VIII NIH Toolbox Cognitive Battery (CB): Composite Scores of Crystallized, Fluid, and Overall Cognition. Monogr Soc Res Child Dev 78: 119-132.

41. Bosscher RJ, Smit JH (1998) Confirmatory factor analysis of the General Self-Efficacy Scale. Behav Res Ther 36: 339-343.

42. Patten SB, Lavorato DH, Metz LM (2005) Clinical correlates of CES-D depressive symptom ratings in an MS population. Genl HospPsychiatry 27: 439-445.

43. Broderick Joan E, Morgan DeWitt Esi, Rothrock Nan, Crane Paul K, Forrest Christopher B (2013) Advances in Patient Reported Outcomes: The NIH PROMIS Measures. eGEMs 1.

44. Garin O, Ayuso-Mateos JL, Almansa J, Nieto M, Chatterji S, et al. (2010) Validation of the "World Health Organization Disability Assessment Schedule, WHODAS-2" in patients with chronic diseases. Health Qual Life Outcomes :51.

45. Petersen RC, Stevens JC, Ganguli M, Tangalos EG, Cummings JL, et al. (2001) Practice parameter: early detection of dementia: mild cognitive impairment (an evidence-based review). Neurology 56: 1133-1142. 